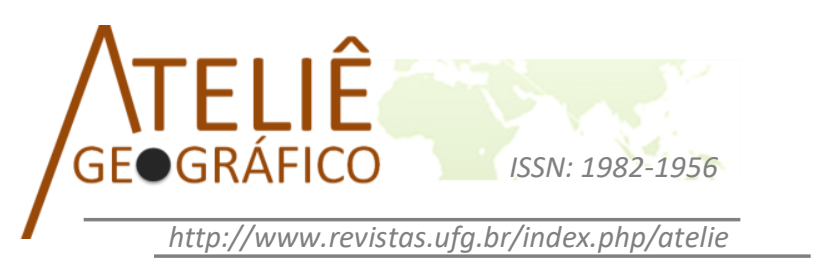

\title{
As contribuições do Programa Institucional de Bolsa de Iniciação à Docência para a formação de professores de Geografia
}

\author{
Las contribuciones del Programa Institucional de Subvención de \\ Iniciación a la Enseñanza para la formación de profesores de Geografía
}

\section{The contributions of the Institutional Program of Teaching Initiation Schoolarship for Geography teachers' training}

\author{
Míriam Aparecida Bueno \\ Universidade Federal de Goiás \\ miriam.cerrado@gmail.com \\ Eliana Marta Barbosa de Morais \\ Universidade Federal de Goiás \\ elianamarta.ufg@gmail.com
}

\begin{abstract}
Resumo
Objetiva-se neste artigo analisar as contribuições do Programa Institucional de Bolsa de Iniciação à Docência (PIBID) para a formação de professores de Geografia do Instituto de Estudos Socioambientais (IESA) da Universidade Federal de Goiás (UFG). Ressaltam-se, a partir dos documentos elaborados pelo governo federal, os objetivos do PIBID, ao mesmo tempo em que se questiona a relevância desse programa para responder às demandas da sociedade atual. Soma-se a esse debate o diálogo realizado em torno do trabalho desenvolvido pelo PIBID de Geografia IESA/UFG, mediante a análise de suas atividades. Considerando o cenário brasileiro, avalia-se esse programa destacando suas possibilidades, no que se circunscreve à sua continuidade ou ruptura, por meio do debate travado com a promulgação/revogação da Portaria $n^{\circ} 46 / 2016$, que versava sobre a reorganização do PIBID. O debate sobre as instabilidades que cercam esse programa insere-se em um contexto de vulnerabilidades políticas no Brasil, atingindo diretamente a educação, que por sua vez envolve, dentre outros, a formação docente, em nível superior, e a atuação docente, na Educação Básica.
\end{abstract}

Palavras-chave: Políticas Educacionais. PIBID. Formação de professores. Geografia.

\section{Resumen}


Este artículo tiene como objetivo analizar las contribuciones del Programa Institucional de Subvención de Iniciación a la Enseñanza (PIBID) para la formación de profesores de Geografía del Instituto de Estudios Socio-Ambientales (IESA), de la Universidad Federal de Goiás (UFG). Destacan, de los documentos aportados por el gobierno federal, los objetivos del PIBID, mientras se cuestiona la relevancia de este programa para satisfacer las demandas de la sociedad actual. Por ello, llevó a cabo el diálogo sobre el trabajo del PIBID de Geografía del IESA /UFG, a través del análisis de sus actividades. Teniendo en cuenta el escenario brasileño, evaluamos este programa destacando sus posibilidades, en el que se limita a su continuidad o ruptura, a través del debate promovido con la promulgación/anulación del Decreto 46/2016, alrededor de la reorganización del PIBID. El debate sobre las inestabilidades que rodean este programa se presenta en un contexto de vulnerabilidades políticas en Brasil, llegando directamente a la educación, que a su vez implica, entre otros, la formación del profesorado en la Educación Superior, y la práctica de la enseñanza en la Educación Básica.

Palabras-clave: Políticas Educativas. PIBID. Formación de profesores. Geografía.

\begin{abstract}
This article aims to analyze the contributions of the Institutional Program of Teaching Initiation Scholarship (PIBID) for Geography teachers' training at the Institute of Socioenvironmental Studies (IESA) at the Federal University of Goiás (UFG). From documents elaborated by the federal government, we highlight the objects of PIBID at the same time that we question the relevance of this program as an answer to the demands of our current society. We add to this discussion the dialogue about the work developed by PIBID in Geography (IESA/UFG) through an analysis of its acitivities. Considering the Brazilian scenario, we evaluate this program, highlighting its possibilities about its continuity or rupture trhough a debate started with the promulgation/revocation of the Ordinance $\mathrm{n}^{\circ} 46 / 2016$, which ruled the reorganization of PIBID. The debate about the instabilities around this program is inserted in a context of political vulnerability in Brazil, which directly affects the education which, in turn envolves, amongst others, teacher training in high level, and teaching performance, in basic education.
\end{abstract}

Keywords: Educational Policies. PIBID. Teacher Training. Geography.

\title{
Introdução
}

Nas pesquisas desenvolvidas atualmente na área de ensino, as discussões em torno da formação de professores têm ganhado êxito, no que circunscreve tanto aos saberes necessários à sua atuação (PIMENTA, 1998; GAUTHIER, 1998; SHULMAN, 2001, 2005; TARDIF, 2008; NÓVOA, 2009) quanto às políticas curriculares que direcionam essa formação (BRASIL, 2002; LOPES; MACEDO, 2011). Esse fato advém da importância dos professores, na condição de mediadores desse processo, na Educação Básica.

Embora a importância desse sujeito para a construção do conhecimento seja reconhecida por diferentes segmentos da sociedade, verifica-se que questões como desprestígio, desvalorização profissional, condições de trabalho inadequadas e atividades cotidianas dissociadas das problemáticas sociais se constituem em elementos de reflexão constante sobre o fazer docente. E como resultado desse processo observase a "desistência" do professor em atuar na docência ou, ainda mais preocupante, o "preenchimento desse cargo" por profissionais alheios ao papel que deve ser exercido 
pelos professores, no que diz respeito à formação do aluno e à atuação desse profissional na sociedade.

Uma das alternativas propostas pelo governo federal brasileiro direcionou-se à qualificação da formação docente mediante a criação do Programa Institucional de Bolsa de Iniciação à Docência - PIBID. Com esse programa buscava-se, em especial, aproximar o futuro professor das problemáticas que ele vivenciaria na prática profissional, auxiliando-o a refletir e construir conhecimentos que o ajudassem na sua inserção e permanência nessa profissão. Isso pode ser observado no posicionamento do presidente da Coordenação de Aperfeiçoamento de Pessoal de Nível Superior (Capes), conforme transcrito a seguir:

\begin{abstract}
Para a Capes, a valorização do magistério decorre de uma política de Estado que atraia novos profissionais, mantenha na rede os já atuantes e assegure o reconhecimento da sociedade ao trabalho docente. Essa política envolve plano de carreira, salário digno, formação inicial e continuada articulada à progressão funcional, boas condições físicas e tecnológicas nas escolas, clima organizacional que motive professores e alunos para o ensino e a aprendizagem, jornada de trabalho integral e, ainda, gestão escolar comprometida com o sucesso escolar de todos. Sendo, portanto, a atribuição legal dessa instituição os aspectos relacionados à formação, é nesse segmento que são concentradas as ações. (GATTI; ANDRÉ, 2014, "Apresentação").
\end{abstract}

Portanto, é com o intuito de favorecer a formação inicial dos futuros professores para atuar na Educação Básica que a Capes instituiu o PIBID. Trata-se de um programa do governo federal brasileiro que tem por finalidade fomentar a iniciação à docência, mediante o aperfeiçoamento da formação de docentes em nível superior e a melhoria da qualidade da Educação Básica, de instituições públicas brasileiras (BRASIL, 2007).

De acordo com a Capes, o PIBID está inserido numa matriz educacional que articula três vertentes: busca pela excelência e pela equidade na formação dos professores brasileiros; integração entre programas de pós-graduação, cursos de formação de professores e escola básica; e produção e disseminação de conhecimento. (CAPES, 2014).

Dessa forma, programas como o PIBID podem favorecer uma formação que garante o direito de aprender dos professores, com base em projetos pedagógicos que contemplem a conexão entre teoria e prática; a integração entre as escolas e as instituições formadoras; o equilíbrio entre conhecimento, competências, atitudes e a ética que realce a responsabilidade social da profissão e que promova a articulação entre ensino, pesquisa e extensão.

Este trabalho surge, portanto, com o intuito de discutir as contribuições do PIBID, no contexto ora apresentado, para a qualificação da formação dos professores que atuam na Educação Básica e, em especial, quando o foco são as contribuições desse programa da Universidade Federal de Goiás (UFG) para a formação inicial e continuada de professores de Geografia.

Essa discussão se assenta nos seguintes questionamentos: Em que contexto a Geografia iniciou a sua participação nesse programa? Como o 
PIBID/Geografia/IESA/UFG se organiza para auxiliar na formação inicial dos futuros professores, dos professores que atuam na Educação Básica e dos alunos das escolas parceiras? O PIBID tem, de fato, contribuído para a qualificação docente e para a permanência do professor na Educação Básica?

Para ajudar nessas reflexões, estruturou-se o presente texto em três partes. Na primeira, intitulada "PIBID: entre as proposições do governo federal e a organização das IES", apresenta-se a espacialização do PIBID no território nacional, momento em que se discutem seus objetivos e questiona-se a relevância desse programa para responder às demandas da sociedade atual. Na segunda parte, denominada "As contribuições do PIBID para a formação do professor de Geografia”, discutem-se os resultados do trabalho desenvolvido pelo PIBID de Geografia da UFG, por intermédio da análise da organização desse programa e das atividades desenvolvidas. Na terceira parte, intitulada "Continuidade ou ruptura? O PIBID no cenário brasileiro", discutemse as avaliações realizadas em torno desse programa e suas possibilidades após a revogação da Portaria $n^{\circ}$ 46/2016, que versava sobre a reorganização do PIBID. Nas considerações finais destacam-se as instabilidades que cercam esse programa, visto que, embora essa portaria tenha sido revogada, ainda não foram delineadas propostas concretas que visassem à continuidade desse programa. E, em contrapartida, foram apresentadas medidas que nos levam a questionar o futuro da formação docente, tais como as propostas na Proposta de Emenda Constitucional (PEC 55) e na reforma do Ensino Médio.

\section{PIBID: entre as proposições do governo federal e a organização das IES}

O PIBID é um programa de incentivo e valorização do magistério e de aprimoramento do processo de formação de docentes para a Educação Básica. Oferece bolsas para que alunos de licenciatura exerçam atividades pedagógicas em escolas públicas de Educação Básica, contribuindo para a integração entre teoria e prática, para a aproximação entre universidades e escolas e para a melhoria da qualidade da educação brasileira. Para assegurar os resultados educacionais, os bolsistas são orientados por coordenadores de área - docentes das licenciaturas, e por supervisores -, docentes das escolas públicas onde exercem suas atividades. O diálogo e a interação entre licenciandos, coordenadores e supervisores geram um movimento dinâmico, de formação recíproca e crescimento contínuo. A figura a seguir ilustra a estrutura do PIBID. 


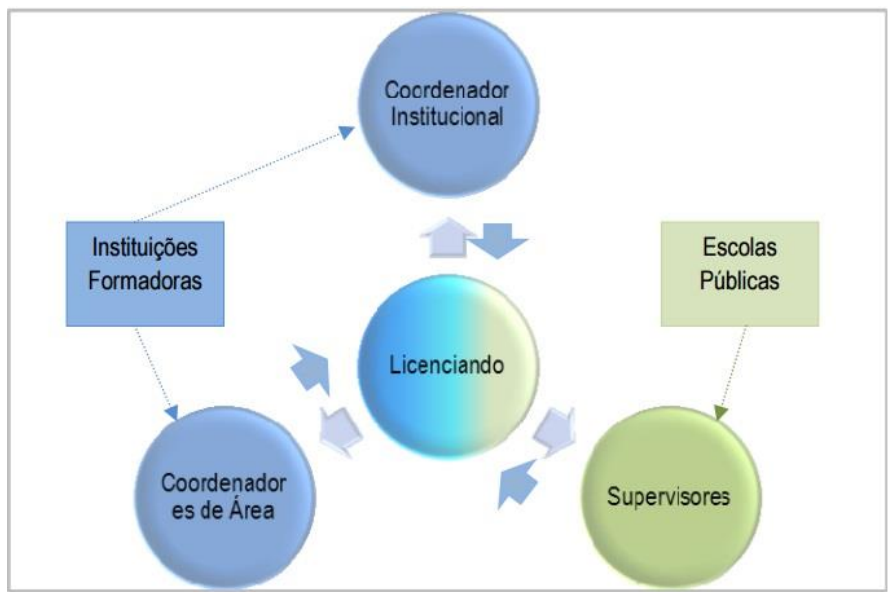

Figura 1 - Estrutura do Programa Institucional de Bolsas de Iniciação à Docência - PIBID.

Fonte: CAPES, 2014.

Ao ser lançado em 2007, as prioridades de atendimento do PIBID eram as áreas de Física, Química, Biologia e Matemática para o Ensino Médio - dada a carência de professores nessas disciplinas. Como os primeiros resultados foram positivos, a partir de 2009 o programa passou a atender toda a Educação Básica, incluindo Educação de Jovens e Adultos, Indígenas, Campo e Quilombolas (PIBID, 2011).

Posteriormente, a partir do edital de 2011, a definição dos níveis a serem atendidos e a prioridade das áreas ficaram a critério das instituições participantes, em diálogo com as redes de ensino e verificada a necessidade educacional e social, do local ou da região. Foi nesse contexto que se estabeleceu o PIBID Interdisciplinar. No edital seguinte, de 2013, é quando ocorre a maior expansão do programa. Para se ter uma ideia, em 2009 o PIBID estava presente em apenas 43 IES, em 2014 esse número passou para 284, contemplando todas as regiões do território nacional (PIBID, 2011).

Os princípios sobre os quais se constrói o PIBID estão de acordo com os estudos de Nóvoa (2009) sobre formação e desenvolvimento profissional de professores. Para tanto, a formação de professores deve ser referenciada no trabalho escolar e na vivência de casos concretos; na combinação entre o conhecimento teórico e metodológico dos professores das IES e entre o conhecimento prático e vivencial dos professores das escolas públicas; na investigação e na pesquisa; bem como no diálogo e trabalho coletivo, realçando a responsabilidade social da profissão.

O PIBID, nessa vertente, tem como princípio a construção de conhecimentos dos sujeitos que estão implicados no processo: licenciandos, professores da Educação Básica e professores das IES. Por conseguinte, as atividades são organizadas de modo a 
valorizar a participação desses sujeitos como protagonistas de sua própria formação, tanto na escolha das estratégias e planos de ação como na definição e na busca dos referenciais teórico-metodológicos que dão suporte à constituição de uma rede formativa.

No âmbito da UFG, o PIBID iniciou suas atividades em 2008 e se distribuiu em quatro regionais, conforme pode ser verificado na figura a seguir (Figura 2).

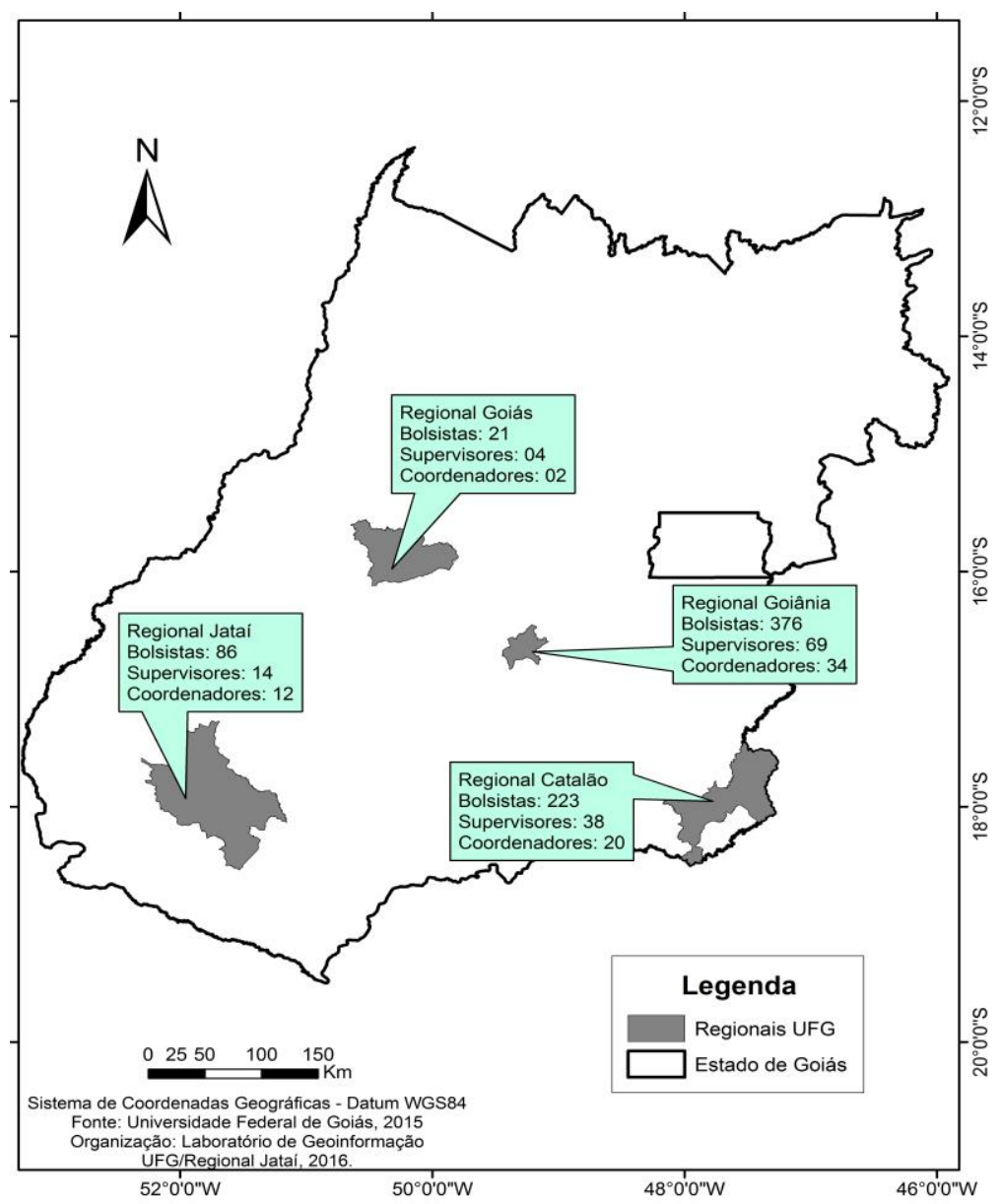

Figura 2 - Participantes do PIBID, por regionais, na UFG, 2016.

Fonte: Carvalho (2016).

Vinculado a um projeto institucional, o PIBID/UFG, cujo coletivo de coordenadores de área, professores supervisores e alunos de graduação tem sido 
ampliado ao longo dos anos, se insere no cotidiano de escolas das redes estadual e municipal do estado de Goiás, contemplando licenciandos de diferentes cursos.

A origem do PIBID na UFG situa-se no ano de 2008. No projeto institucional, apresentado nesse ano, denominado "Formação de professores em ciências e matemática" (Edital MEC/CAPES/FNDE/2008), foram contemplados os cursos de Química, Física, Biologia e Matemática, nos Câmpus de Goiânia, Catalão e Jataí, conforme proposto para a primeira versão do PIBID no cenário nacional. Nesse edital foram contempladas quarenta e quatro bolsas de iniciação à docência, doze bolsas de coordenação e onze bolsas de supervisão. Embora as atividades desde o início do PIBID fossem desenvolvidas em grupo, tratava-se de grupos menores, formados especialmente por um coordenador de área, um supervisor e um grupo pequeno de alunos, em geral seis alunos da graduação, dos quais se exigia que não estivessem cursando o primeiro período.

Em 2009, com o intuito de dar continuidade ao PIBID foi desenvolvido o projeto "Formação Inicial de professores na UFG", contemplado no Edital Capes $\mathrm{n}^{\circ}$ 2/2009 - PIBID (PIBID, 2011). Nesse projeto entraram os cursos de Filosofia, LetrasPortuguês, Artes Visuais, Educação Física e Música no Câmpus Goiânia; Educação Física e Pedagogia no Câmpus Catalão, e Matemática no Câmpus Jataí. Foram concedidas cento e quatorze bolsas de iniciação à docência, oito bolsas de coordenação e dezoito bolsas de supervisão. Comparativamente ao edital anterior, verificou-se um aumento no número de bolsas de iniciação à docência concedidas. Em detrimento da oscilação do quantitativo das bolsas de coordenador de área e de supervisor, evidenciase a presença de grupos maiores em paralelo a um grupo maior de alunos sob a responsabilidade de um coordenador de área.

No projeto institucional apresentado em 2011, denominado Formação docente, profissionalização e práticas pedagógicas na UFG (Edital no 1/2011/Capes) foram contemplados os cursos de Artes Cênicas, Biologia, Física, Geografia, Matemática, Pedagogia e Química no Câmpus de Goiânia; Ciências Biológicas, Física, Geografia, História, Matemática e Química no Câmpus de Catalão; Filosofia na Cidade de Goiás; e Física e Química em Jataí, totalizando noventa e nove bolsistas, dezesseis supervisores e dezesseis coordenadores de área. Não percebemos grandes alterações nesse edital, comparativamente ao edital de 2009. Uma das maiores mudanças sofridas nos editais do PIBID irá ocorrer em 2013.

No projeto institucional apresentado em 2013, com a temática Formação de professores e desenvolvimento da profissão docente: reflexões e ações acerca de seus impactos na cultura escolar (Edital $n^{\circ}$ 61/2013, retificado), passaram a compor o PIBID da UFG as licenciaturas em Artes Visuais, Ciências Biológicas, Ciências Sociais, Dança, Educação Física, Enfermagem, Música (Educação Musical, Ensino do Canto, Ensino do Instrumento), Filosofia, Física, Geografia, História, Letras-Libras, Letras- Espanhol, Letras-Francês, Letras-Inglês, Letras-Português, Matemática, 
Pedagogia, Psicologia e Química (CAPES, 2014). Nesse período, houve um aumento dos cursos de licenciaturas atendidos e um aumento no número de bolsas, de forma geral. As bolsas de iniciação à docência foram para 705, as de supervisão saltaram para 125 , coordenadores de área 68 , totalizando 898 bolsas.

$\mathrm{O}$ aumento do quantitativo de sujeitos envolvidos no PIBID deve ser visto a partir de uma perspectiva qualitativa, pois se trata de um programa que, ao qualificar a formação e a atuação docente, justifica a importância de implementação de projetos educacionais nos diversos componentes curriculares que fazem parte da Educação Básica, nas diferentes áreas do território nacional. Portanto, ele deve ser planejado não como uma política que atenda parcialmente aos futuros professores e sim ir em direção ao atendimento da totalidade dos sujeitos envolvidos com a formação docente.

A despeito de reconhecermos que houve avanços do PIBID para a formação de professores na UFG, sabemos que ainda há muito a contribuir para a formação desse docente para atuar na Educação Básica. Se o PIBID não visa à superação de todos os dilemas postos por essa formação, é sabido, entretanto, que ele se configura numa importante política educacional voltada para sanar, ou mesmo diminuir, alguns dos dilemas que envolvem essa formação.

\section{As contribuições do PIBID/UFG/Goiânia para a formação do professor de Geografia}

Sabe-se que a formação do professor de Geografia passou por intensas mudanças no final do século passado, com destaque, dentre outros, para a emersão de novos olhares às perspectivas clássicas de explicação dos fenômenos mundiais e para a necessidade de uma visão cultural mais heterogênea visando entender a sociedade atual. Ou seja, a visão moderna de ciência e de conhecimento é questionada na compreensão da realidade atual. Nessa crise do conhecimento tradicional, inserem-se a escola, a Geografia e os processos de ensino nela envolvidos. Para isso, há de se pensar em um professor capaz de levar a cabo novas formas de ensinar e, da mesma forma, novos modelos de aprendizagem e de construção do conhecimento geográfico.

Além das políticas oficiais de formação de professor, é preciso desenvolver ações práticas com objetivo de demonstrar que uma nova Geografia Escolar é um modelo alternativo de ensino possível. Para isso, tem-se demonstrado, cada vez mais, a necessidade de instituir redes de investigadores, alunos e professores da escola. Estes deverão ser capazes de desenvolver propostas de ensino de Geografia mais significativas para o aluno e, com isso, favorecer a formação e a profissionalidade docente, de forma que o currículo escolar e as práticas de ensino se constituam como foco central para o desenvolvimento de modelos alternativos de ensino, de escola, de Geografia e de formação de professor.

Nesse sentido, a proposta de formar professores para fazer frente a essa problemática toma a realidade escolar como aspecto central para o modelo alternativo. 
Portanto, a formação do professor decorrerá do intenso processo de investigação na escola (PÓRLAN; RIVERO, 1998; GARCIA-PÉREZ, 2000). Essa investigação é entendida como sendo a forma pela qual o modelo se configura como proposta alternativa de educação e, por conseguinte, capaz de superar os modelos tradicionais de ensino. O processo investigativo é o mais compatível com a ideia de construção de conhecimento, de visão complexa da realidade social, cultural e ambiental, dentre outras que possam superar o reducionismo dos processos de ensino.

Para a efetivação de uma concepção de pesquisa que possibilite a efetivação de práticas escolares capazes de cumprir esse papel, deve-se levar em conta um modelo de pesquisa capaz de formar um profissional crítico e, ao mesmo tempo, ser realizável no âmbito escolar. Lüdke (2001) aponta que nem sempre as condições para a realização da pesquisa no âmbito escolar garantem a sua efetivação. Para a autora, é necessário que o professor esteja imbuído de uma cultura sobre o significado da pesquisa na prática e na construção do conhecimento, e alerta para as concepções de pesquisa acadêmica que nem sempre são compatíveis com a pesquisa escolar.

Apesar de ser forte a representação da concepção acadêmica de pesquisa no âmbito escolar, vários autores apontam para a necessidade de uma didatização da ideia de pesquisa para as práticas escolares. Demo (2005) assinala que a pesquisa deve ser o princípio da ação docente no âmbito escolar. Para o autor, se a escola quer ser diferente dos diversos espaços educativos existentes na sociedade, ela deve adotar procedimentos que sejam pautados pela ação crítica reflexiva.

Com a reflexão crítica é possível conhecer os processos pelos quais os alunos constroem seus conhecimentos sobre a Geografia e sobre a escola. Cavalcanti (2006) refere que o papel essencial da Didática da Geografia consiste na tarefa de auxiliar o professor a conhecer as dificuldades que imperam no âmbito escolar e construir alternativas de ensino de maneira que os alunos estruturem um aprendizado de Geografia com significado para a sua vida.

$\mathrm{O}$ que se constata é que a universidade encontra-se muito distante da escola e isso dificulta a formação do futuro professor. É na escola que os alunos do curso de licenciatura buscam a realização profissional. Refletir sobre a formação do professor significa repensar a importância dessa articulação no currículo das licenciaturas, contribuindo para a profissão docente e incentivando-a.

É assentado nessa proposta que o PIBID/Geografia da UFG da Regional de Goiânia foi estruturado. Buscou-se, dessa maneira, estimular a formação inicial e continuada dos sujeitos envolvidos com base em atividades que seriam planejadas e desenvolvidas semanalmente pelo coletivo de sujeitos que o compõem.

Foram definidos três encontros semanais orientados para os momentos de planejamento, estudos e intervenções. Compõem o grupo PIBID/IESA/UFG bolsistas (vinte e dois), professores supervisores (quatro) e coordenadores de área (dois), totalizando vinte e oito pessoas. Para favorecer o diálogo e o acompanhamento foram 
formados quatro grupos, contendo cada um destes um professor supervisor e cinco ou seis alunos.

Definimos as segundas-feiras, das $14 \mathrm{~h}$ às $17 \mathrm{~h}$, como período dedicado ao planejamento. Nesses momentos se discutem as questões de ordem administrativa e pedagógica que possuem aspectos mais gerais, são planejadas as atividades semanais, ou as atividades mais usuais do PIBID, bem como são planejadas a participação e a organização de eventos.

As quartas-feiras, das $14 \mathrm{~h}$ às $17 \mathrm{~h}$, configuram-se como outro dia dedicado especificamente às atividades do PIBID. Nesse dia o horário é destinado à participação em grupos de estudos e pesquisas sediados no Laboratório de Estudos e Pesquisas em Educação Geográfica (LEPEG). Atualmente, os grupos dos quais os alunos e professores supervisores participam são o Núcleo de Estudos e Pesquisas em Geografia, Ensino e Ambiente (NúcleoGEA), o Grupo de Estudos de Cartografia para Escolares (GECE) e o Núcleo de Pesquisa em Ensino de Cidade (NUPEC), todos destinados a discutir a Geografia Escolar.

A definição do outro encontro semanal é realizada internamente nos grupos, dada a compreensão de que é preciso levar em consideração as disciplinas cursadas pelos alunos em formação e o horário de aula do professor que atua na educação básica. Esses são os momentos de intervenções pedagógicas. Momentos em que os alunos, após um planejamento prévio, assentado na análise de materiais de diferentes naturezas, propõem e executam aulas na educação básica.

A partir dessas atividades almejávamos ações docentes que contribuíssem para a formação dos alunos bolsistas, dos supervisores e dos alunos da Educação Básica. Com a efetivação das atividades desenvolvidas nesses encontros propunha-se formar e aperfeiçoar difusores de conhecimento em ciências geográficas; aprimorar a formação contínua do educador, juntamente com o aluno licenciando; elevar a qualidade das ações acadêmicas voltadas para a formação inicial de professores e para a valorização do espaço escolar público, oportunizando, portanto, práticas escolares articuladas à realidade local.

Considerando as experiências desenvolvidas ao longo desses sete anos do PIBID/UFG da Regional de Goiânia, consideramos que houve um fortalecimento do conhecimento desses acadêmicos em relação à práxis pedagógica de Geografia, graças à interação com professores e colegas; à convivência no dia a dia das escolas; às atividades desenvolvidas nos momentos de planejamento, estudos e intervenções; à participação em atividades de formação diversas, como a organização de eventos, a publicação e/ou a apresentação de trabalhos.

Refletindo sobre o contexto político que o Brasil atravessa, consideramos que esse é um bom momento para dialogar sobre a importância desse programa para a formação docente. Esse é o tema que discutiremos a seguir. 


\section{Continuidade ou ruptura? O PIBID no cenário brasileiro}

O PIBID está em atividade no Brasil há oito anos, tendo passado de 3.088 bolsistas, distribuídos em 43 instituições em 2009, para um total de 90.254 bolsistas, espalhados em 284 instituições, em 2014 (CAPES, 2014). Esse crescimento evidencia tanto a dimensão quantitativa desse programa como a aposta que os cursos de licenciatura fizeram nele, para qualificar a formação inicial dos professores, evidenciada na adesão dessas instituiçõos. Várias críticas têm surgido, no meio acadêmico, quanto às reais contribuições desse programa para a qualificação da formação dos licenciandos e da prática profissional nos diferentes componentes curriculares. Todavia, não aprofundaremos essa questão, por não ser esse o objetivo do presente artigo.

Durante esse período foram realizadas diversas avaliações do programa (artigos, teses, dissertações), as quais objetivavam refletir sobre as contribuições do PIBID para problematizar questões referentes ao cotidiano escolar.

Em uma parceria empreendida pelo Ministério da Educação (MEC) e pela Organização das Nações Unidas para a Educação, a Ciência e a Cultura (UNESCO), foram analisadas as contribuições do PIBID para a Educação no território brasileiro. (GATTI; ANDRÉ, 2014).

As análises feitas se fundamentaram em questões relativas ao currículo da formação inicial, aos pressupostos que orientam os cursos de formação de professores e à necessidade de aproximar o campo de formação e de atuação profissional.

$\mathrm{Na}$ análise verificou-se que o PIBID é valorizado por todos os sujeitos que o compõem: coordenador institucional, coordenador de área, professores supervisores e alunos bolsistas. Essa valorização assenta-se, dentre outros, nos seguintes aspectos: a) contribuições para os cursos de licenciatura: valorização, fortalecimento e revitalização das licenciaturas e da profissão docente; e permanência dos estudantes nas licenciaturas, para a redução da evasão e para atrair novos estudantes; b) contribuições para os estudantes bolsistas: proporciona contato direto com a escola pública; permite a aproximação entre teoria e prática; estimula a iniciativa, a criatividade, e o espírito investigativo; c) contribuições para os professores supervisores da escola: propicia uma formação continuada, estimula a busca de novos conhecimentos e a continuidade de estudos; aproxima o professor do meio acadêmico; possibilita a reflexão sobre a prática e o questionamento construtivo; favorece o desenvolvimento de estratégias de ensino diversificadas e o uso de laboratórios e outros espaços; valoriza e reconhece o professor e seu trabalho na escola; d) para os professores das IES: favorece sua aproximação com a realidade e necessidades da escola básica; contribui para a modificação de posturas dos docentes do curso de licenciatura; ajuda a questionar a qualidade das práticas formativas no âmbito da docência; e) para as escolas e seus alunos: estimula o desenvolvimento de estratégias de ensino diversificadas e motivadoras; promove melhorias na qualidade do ensino com novas formas de ensino; aumenta o interesse dos 
alunos pelas disciplinas e pelas atividades escolares; melhora o desempenho dos alunos e aumenta sua autoestima; f) na relação IES e Escola Pública: favorece um diálogo mais efetivo entre a IES e as escolas públicas de Educação Básica, renovando práticas e reflexões teóricas; propicia avanço das pesquisas voltadas ao ensino; cria ações compartilhadas entre licenciandos bolsistas, professores supervisores e coordenadores de área; estimula e favorece o trabalho coletivo; fortalece e valoriza o magistério e o trabalho do professor na escola; g) como política pública de educação: contribui para a valorização da profissão de professor; constitui-se em rara política de atenção à formação inicial dos professores para a Educação Básica; é um programa que desacomoda as licenciaturas e mobiliza escolas. (GATTI; ANDRÉ, 2014).

Com base nesses aspectos, sugeriram-se a continuidade do programa como proposta permanente, a ampliação do programa e a construção de indicadores de avaliação do programa para orientar a gestão (administrativa e pedagógica).

Embora os representantes da CAPES tenham evidenciado a necessidade de aperfeiçoar o programa, temos visto outros desdobramentos no cenário nacional, como a proposta apresentada com a publicação da Portaria no 46/2016, recentemente revogada, que aprovava o Regulamento do Programa Institucional de Bolsa de Iniciação à Docência - PIBID. Ainda que essa portaria tenha sido revogada, a instabilidade gerada por sua aprovação faz parte do cenário atual de permanência, ampliação e mudanças sentidas no interior desses programas.

É nesse contexto que acreditamos serem válidas as discussões apresentadas por essa portaria, visto que não foi apresentada, até o momento, outra alternativa para a organização do PIBID no cenário nacional. Além do mais, ao conhecê-la, podemos, inclusive, lutar para que elementos apresentados em seu interior não sejam retomados em propostas futuras, dadas as divergências apresentadas, por membros da Capes, quanto à revogação dessa portaria.

Dentre as mudanças contempladas nessa portaria $\left(n^{\circ} 46\right.$, de 11 de abril de 2016) destacava-se a reorganização do quantitativo de sujeitos envolvidos diretamente com o PIBID: cada coordenador de área deveria orientar no mínimo vinte e no máximo (trinta) bolsistas de iniciação à docência; cada supervisor deveria acompanhar no mínimo dez e no máximo quinze bolsistas de iniciação à docência.

Se colocada em prática, essa proposta reorientaria as dinâmicas que estavam sendo desenvolvidas no PIBID até o momento. Ou seja, sairíamos de um mínimo de dez bolsistas por coordenador de área para vinte; teríamos um mínimo não mais de cinco bolsistas por professor supervisor, mas de dez. Esses fatores poderiam comprometer a qualidade das atividades de acompanhamento desenvolvidas por esses sujeitos, tanto no momento em que eles planejam ou executam uma intervenção quanto nos momentos em que eles pesquisam, redigem ou apresentam um trabalho em evento científico. 
A duração das bolsas de iniciação à docência passaria a ser de doze meses, prorrogáveis por igual período, não sendo pagas nos meses em que houver greve ou suspensão relevante do período letivo nas escolas da Educação Básica. De igual maneira, sairíamos de um processo em que os alunos poderiam ter sua formação ampliada durante toda a graduação, cuja bolsa, na maioria dos casos, permite a sua permanência no curso, para a passagem curta por um programa, que pode não trazer tantos benefícios em virtude do seu desligamento. Soma-se a isso o fato de utilizar um programa que visa qualificar a docência, para inibir movimentos que buscam, de igual maneira, valorizar a docência quando lutam por seus direitos.

Outro agravante dessa portaria dizia respeito às IES que poderiam participar ou não do edital, quando propunha que somente poderiam aderir a esta "pactuação", termo utilizado no próprio documento, aquelas que possuíssem projetos institucionais do PIBID, selecionados por meio do Edital CAPES/DEB $\mathrm{n}^{\circ}$. 61, de 2013, regido pela Portaria 96/2013. Este fato evidencia o contingenciamento imposto a esse programa. Soma-se a esse aspecto o fato de terem sido extintos outros componentes curriculares, como Artes e Educação Física, por exemplo, ou projetos interdisciplinares, conforme pode ser visto a seguir.

Quadro 1 - Eixos estruturantes para a organização dos projetos institucionais do PIBID, 2016.

\begin{tabular}{|c|c|c|c|}
\hline $\begin{array}{c}\text { Níveis/etapas de } \\
\text { ensino }\end{array}$ & Eixos estruturantes & Subeixos estruturantes & Licenciaturas articuladoras \\
\hline $1^{\circ}$ ao $3^{\circ}$ anos do EF & Alfabetização e numeramento & $\begin{array}{c}\text { Alfabetização e } \\
\text { numeramento }\end{array}$ & Pedagogia \\
\hline \multirow{3}{*}{$4^{\circ}$ ao $9^{\circ}$ anos do $\mathrm{EF}$} & \multirow{3}{*}{ Letramento } & $\begin{array}{c}\text { Letramento em Língua } \\
\text { Portuguesa } \\
\end{array}$ & Letras \\
\hline & & Letramento Matemático & Matemática \\
\hline & & Letramento Científico & Ciências, História e Geografia \\
\hline \multirow{4}{*}{ Ensino Médio } & \multirow{4}{*}{$\begin{array}{l}\text { Áreas de Conhecimento do } \\
\text { Ensino Médio }\end{array}$} & $\begin{array}{c}\text { Linguagens, códigos e suas } \\
\text { tecnologias }\end{array}$ & Letras \\
\hline & & $\begin{array}{l}\text { Matemática e suas } \\
\text { tecnologias }\end{array}$ & Matemática \\
\hline & & $\begin{array}{c}\text { Ciências da Natureza e suas } \\
\text { tecnologias }\end{array}$ & Biologia, Química e Física \\
\hline & & $\begin{array}{l}\text { Ciências Humanas e suas } \\
\text { tecnologias }\end{array}$ & $\begin{array}{c}\text { Geografia, História, Filosofia e } \\
\text { Sociologia }\end{array}$ \\
\hline
\end{tabular}

Fonte: CAPES, 2016.

Quanto ao projeto institucional, este deveria adequar-se para ser desenvolvido em parceria com os sistemas de ensino de Educação Básica, em escolas públicas consideradas prioritárias e articuladas com os programas institucionais do MEC: Programa Nacional de Alfabetização na Idade Certa (PNAIC), Programa Mais Educação (PME), Programa Ensino Médio Inovador (Proemi) e Pacto pelo Fortalecimento do Ensino Médio (PNEM), sendo apresentada pela Capes, inclusive, uma relação de escolas elegíveis para a participação no PIBID.

A par dessas análises e daquelas respaldadas no debate que tem ocorrido no cenário nacional (Reforma do Ensino Médio/BNCC e Escola Sem Partido e PEC 
241/55) temos tido dificuldades em falar de forma mais concreta sobre os rumos do PIBID. Podemos adiantar apenas que os rumos desse programa seguem pari passu à maneira como a educação é tratada no Brasil, no que circunscreve a uma política de Estado.

\section{Considerações Finais}

O discurso apresentado pela Capes é o de que o PIBID é um programa de incentivo e valorização do magistério e de aprimoramento do processo de formação de docentes para a Educação Básica. Vimos nas avaliações realizadas por diferentes vias que esse objetivo tem sido atingido, ainda que sejam apresentadas sugestões para a sua melhoria.

Todavia, temos assistido no cenário nacional a incertezas quanto à continuidade e à organização desse programa. Por ora, o grande gargalo dessas incertezas foi a publicação e posterior revogação da Portaria nº 46/2016.

Embora essa portaria tenha sido revogada e tenhamos retornado a organizá-lo segundo o que estava proposto no Edital $n^{\circ}$ 1/2011/Capes, não acreditamos na manutenção do programa tal como vinha sendo desenvolvido. Até porque várias questões postas em sua origem não estão respaldando as ações atuais do PIBID, como auxílio para a participação em eventos, para a aquisição de materiais de consumo e de materiais permanentes, a confecção de materiais, o pagamento de pessoa física e jurídica. Há a necessidade de nos prepararmos para um novo modelo de implementação desse programa, bem como de lutarmos por sua continuidade, numa perspectiva de política de Estado e não de governo.

E é nesse sentido que nós do PIBID/Geografia da UFG da regional de Goiânia damos prosseguimento ao nosso trabalho, acreditando que bons professores podem favorecer a formação de bons cidadãos e no futuro termos caminhos diferentes para a sociedade brasileira, que tão brilhantemente tem atravessado esses momentos de incertezas.

\section{Referências}

BRASIL. Ministério da Educação e do Desporto. Secretaria da Educação Fundamental. Parâmetros Curriculares Nacionais: História e Geografia. Brasília: MEC, 1997a.

BRASIL. Ministério da Educação e do Desporto. Secretaria da Educação Fundamental. Parâmetros Curriculares Nacionais: introdução aos Parâmetros Curriculares Nacionais. Brasília: MEC, 1997b.

BRASIL. Ministério de Educação e Cultura. Resolução CNE/CP 2, de 19 de fevereiro de 2002. Disponível em: 〈http://portal.mec.gov.br/>. Acesso em: 25 jul. 2013.

BRASIL. Lei $n^{\circ}$. 11.502, de 11 de julho de 2007. Modifica as competências e a estrutura organizacional da fundação Coordenação de Aperfeiçoamento de Pessoal de 
Nível Superior - CAPES. Diário Oficial [da] União, Brasília, DF, 11 jul. 2007. p. 5. Disponível em: <http://www.planalto.gov.br/ccivil_03/_Ato20072010/2007/Lei/L11502.htm>. Acesso em: 8 jan. 2016.

BUENO, M. A. Ações do PIBID para a melhoria do ensino de Geografia: reflexões iniciais sobre diferentes estratégias pedagógicas e formação de professores. In: SILVA, E. I.; PIRES, L. M. Desafios da didática de Geografia. Goiânia: Ed. PUC-GO, 2013.

CAPES. Relatório de gestão PIBID 2009-2013. Brasília: Capes, 2014. Disponível em: <https://www.capes.gov.br/images/stories/download/bolsas/2562014-relatrorio-DEB2013-web.pdf>. Acesso em: 15 set. 2015.

CAPES. Portaria $\mathrm{n}^{\circ} 46$, de 11 de abril de 2016. Disponível em: < https://www.capes.gov.br/images/stories/download/legislacao/15042016-Portaria-46Regulamento-PIBID-completa.pdf>. Acesso em: 15 set. 2015.

CARVALHO, L. S. PIBID de Geografia na Universidade Federal de Goiás: proposta e experiências formativas. 2016. Dissertação (Mestrado) - Universidade federal de Goiás, Jataí, GO, 2016.

CAVALCANTI, L. de S. Geografia, escola e construção de conhecimentos. São Paulo: Papirus, 2006.

DEMO, P. Metodologia da investigação em educação. Curitiba: IBPEX, 2005.

GARCIA-PÉREZ, F. F. Los modelos didácticos como instrumento de análisis y de intervención en la realidad educativa. Biblio 3 W Revista Bibliográfica de Geografia y Ciencias Sociales, Barcelona, n. 207, 2000.

GAUTHIER, C. Por uma teoria da pedagogia: pesquisas contemporâneas sobre o saber docente. Ijuí, RS: Ed. Unijuí, 1998.

GATTI, B.; ANDRÉ, M. Um estudo avaliativo do Programa Institucional de Bolsa de Iniciação à Docência (PIBID). São Paulo: Fundação Carlos Chagas/SEP, 2014.

LOPES, A.C.; MACEDO, E. Teorias de currículo. São Paulo: Cortez, 2011.

LÜDKE, M. O professor, seu saber e sua pesquisa. Revista Educação \& Sociedade, ano XXII, n. 74, abr. 2001.

MORAIS, E. M. B.; OLIVEIRA, K. A. T. Estágio Supervisionado e práticas curriculares: uma leitura dos cursos de formação de professores de geografia das Universidades Católica, Estadual e Federal de Goiás. In: CAVALCANTI, L. S. (Org.). Temas geográficos. Goiânia: Ed. UFG, 2008. p. 169-188.

NÓVOA, A. Para uma formação de professores construída dentro da profissão. In: . Professores: imagens do futuro presente. Lisboa: Educa, 2009. p. 25-

46. Disponível em: <http://www.revistaeducacion.educacion.es/re350/re350_09por.pdf >. Acesso em: 7 jun. 2016. 
PIMENTA, S. G. A didática como mediação na construção da identidade do professor: uma experiência de ensino e pesquisa na licenciatura. In: ANDRÉ, M. E. et al. (Org.). Alternativas ao ensino de didática. Campinas: Papirus, 1998. p. 36-69.

PORLÁN, R.; RIVERO, A. El conocimiento de los profesores. Sevilla: Sevilla, 1998. (Serie Fundamentos, 9).

SACRAMENTO, A. C. R.; MORAIS, E. M. B.; OLIVEIRA, K. A. T.; MORAES, L. B. Concepções e particularidades dos currículos no Brasil: compreendendo a Geografia Escolar em Goiás, Rio de Janeiro e São Paulo. In: ENCONTRO ESTADUAL DE DIDÁTICA E PRÁTICAS DE ENSINO - EDIPE, 6., 2015, Goiânia. Anais... Goiânia: Cedep, 2015. p. 1-15.

SCHÖN, D. Formar professores como profissionais reflexivos. In: NÓVOA, A. (Coord.). Os professores e sua formação. Lisboa: Dom Quixote, 1992. p. 77-91.

SHULMAN, L. S. Conocimiento y enseñanza. Revista Estudios Públicos, Chile, v. 83, 2001.

SHULMAN, L. S. Conocimiento y enseñanza: fundamentos de la nueva reforma.

Profesorado: revista de Currículum y Formación del Profesorado Granada-España, ano 9, n. 2, p. 1-30, 2005. Disponível em: <http://www.ugr.es/local/recfpro/rev92art1.pdf>. Acesso em: 27 maio 2009.

TARDIF, M. Saberes docentes e formação profissional. 9. ed. Petrópolis, RJ: Vozes, 2008.

UFG. Projeto institucional do PIBID.

<ttps://pibid.prograd.ufg.br/up/296/o/UFG_PROJETO_INSTITUCIONAL_PIBID_2011.pdf> . Acesso em: 16 janeiro 2016.

\section{Míriam Aparecida Bueno}

Doutora em Geografia pela Universidade Estadual de Campinas, mestre em Geografia pela Universidade Federal de Minas Gerais e graduada pela Universidade Federal do Acre. Atualmente é professora associada do Instituto de Estudos Socioambientais, da Universidade Federal de Goiás.

Avenida Frei Nazareno Confalone, Quadra 27, Lote 22, Setor Goiânia II, Goiânia, GO, CEP 74663-280. miriam.cerrado@gmail.com

\section{Eliana Marta Barbosa de Morais \\ Doutora em Geografia pela Universidade de São Paulo, mestre e graduada em Geografia pela Universidade Federal de Goiás. Atualmente é coordenadora do Programa de Pós- Graduação em Geografia do Instituto de Estudos Socioambientais, da Universidade Federal de Goiás. Avenida Mineira, Quadra 6, Lote 14, Jardim Nova Era, Aparecida de Goiânia, GO, CEP 74916-320. elianamarta.ufg@gmail.com}

